\title{
MEMORIAS DE PABLO NERUDA: CONTRAPUNTO AUTOBIOGRÁFICO EN PROSA Y VERSO
}

\author{
POR \\ ENRIQUE VALDÉs \\ Purdue University-Calumet
}

Este libro póstumo de Pablo Neruda, Confieso que he vivido: memorias (1974), reafirma la vitalidad del género autobiográfico, tan discutida y frecuentemente negada en la tradición hispánica. ${ }^{1}$ Neruda se inscribe en una noble tradición de escritores chilenos que han dejado en sus libros de memorias sus mejores contribuciones a la historia cultural del país y a la historia de la literatura en particular, ${ }^{2}$ desde los Recuerdos del pasado (1910), de Vicente Pérez Rosales hasta el más reciente Memorias de un soldado (1985), de Carlos Pratt, que recogen, al igual que la última parte de las memorias de Neruda, la amarga experiencia de la dictadura militar de 1973 y el quiebre de la tradición democrática en Chile. Es claro que la intención de Neruda no fue escribir una autobiografia, ni hacer el balance de su vida total ni la de los hechos históricos y literarios de una época efervescente. Falta para ello la linealidad del desarrollo temporal. La progresión de los capítulos corresponde más bien a desplazamientos geográficos que a evoluciones vitales, con lo que Neruda elude el cuestionamiento verbal de esta evolución. Se trata de un libro "armado", hecho de retazos de épocas, tiempos y circunstancias diversas, cuya totalidad no desmerece como literatura ni como poesía.

La reticencia de Neruda a completar el trabajo autobiográfico de Confieso que he vivido se fundamenta en el hecho nada insignificante de que el poeta ya había escrito este libro de memorias al cumplir sus sesenta años: Memorial de Isla Negra (1964). Son éstas sus memorias en verso, su verdadera biografia poética, la misma "galería de fantasmas sacudidos por el fuego y la sombra de su época": sus verdaderos recuerdos autobiográficos

\footnotetext{
${ }^{1}$ Son los propios memorialistas los que han difundido la idea de que los españoles son reacios a escribir memorias. Recordemos lo expresado por Goytisolo (1972): "Los españoles se muestran singularmente reticentes a la idea de exponer [la vida] ... por escrito" (14). Hasta culminar con la idea de Ortega de que "las Memorias son un síntoma de complacencia con la vida" y su escasez en España se debe a que para ellos "la vida es como un universal dolor de muelas" $(1947,585)$. Este concepto es refutado en el libro La autobiografia española hasta Torres Villarroel de Randolph Pope (1974).

${ }^{2}$ Alone (Hernán Díaz Arrieta), Memorialistas chilenos (1960). El libro incluye una interesante bibliografia de memorias de 61 escritores chilenos, desde El cautiverio feliz, de Pineda Bascuñán hasta Recuerdos olvidados, de Augusto D'Halmar.
} 
como poeta. ¿Qué es entonces lo que vienen a completar estas confesiones a lo que ya estaba dicho? ¿Qué función cumple y de qué manera se integra este libro dentro de la totalidad de la obra nerudiana? Éstas son las preguntas que necesitamos contestar para desterrar la sospecha de que fue un libro innecesario y desigual, armado a espaldas del autor.

Este estudio se propone la interpretación de estas memorias como un texto lírico y metafórico y compara los procedimientos empleados en la prosa y el verso para el tratamiento de temas autobiográficos siempre constantes en toda la obra de Neruda: la figura del padre y de la madre, el paisaje sureño, las preocupaciones políticas y sociales, las consideraciones éticas y estéticas.

Neruda define la particularidad de sus memorias, sin contradecir en absoluto las precisiones entregadas por Olney $(1972)^{3}$ y Gusdorf $(1980),{ }^{4}$ en el sentido de ser escritura mediatizada y ficcional: metafórica.

Estas memorias o recuerdos son intermitentes y a ratos olvidadizos porque así precisamente es la vida ... una galería de fantasmas sacudidos por el fuego y la sombra de su época. (Confieso 9)

Recuerdos fantasmales e intermitencias de la memoria nos remiten a rasgos propios de la poesía con la que este libro se abraza a cada instante. Los dos primeros libros del Memorial de Isla Negra (1964) siguen casi literalmente la evolución de las confesiones, como si Neruda las hubiera tomado como una fuente de referencia de los recuerdos. Muchos poemas encuentran sus correlatos perfectos en Confieso que he vivido: el liceo de Temuco con su subterráneo húmedo y las peleas con bellotas entre los muchachos, en "El colegio en invierno" (I: 41); ${ }^{5}$ los personajes literarios de Búfalo Bill y Sandokán, la lectura de Salgari que al parecer influyó en toda la literatura chilena de este siglo, la experiencia de ver el mar por primera vez en "El primer mar" (I: 31 ); y la revelación de la sexualidad en "El sexo" (I: 43). A veces, la experiencia se concretiza y se detalla en la prosa. Los lugares adquieren nombres propios, el mar aparece ahora entre dos cerros muy concretos de la geografia chilena: "Allí entre dos grandes cerros (el Huilque y el Maule) se desarrollaba la furia del mar" (Confieso 27). En "El sexo", en cambio, las muchachas, que en el poema reciben los nombres de Rosita y Josefina, son aquí dos vecinitas diabólicas y precoces que han encontrado un nido con huevos de pájaro, de color turquesa, con el que atraen la curiosidad del poeta-niño. Igual que en el poema, la escena termina con los protagonistas escondidos debajo del mostrador de la panadería, luego que el padre hace su entrada intempestiva en la tienda. En este caso, el poema es mucho mas explícito que el texto en prosa. En aquél, las muchachas desvisten y examinan al niño a cambio de su tesoro ecológico y natural. Explícitamente el poeta concluye diciendo: “... yo sentí que cambiaba / algo /

\footnotetext{
3 "Autobiography and poetry are both definitions of the writing self at a moment and in a place" (Olney 1972, 14).

4 "Autobiography is a second reading of experience, and it is truer than the first because it adds to experience itself consciousness of it" (Gusdforf 38).

${ }_{5}^{5}$ Citamos por la primera edicion de 1964 en cinco volúmenes, colocando el número romano para el tomo seguido por la página.
} 
en mi sangre / y que subía a mi boca, a mis manos ... / la flor hambrienta / y pura / del deseo" (I: 48). La referencia de la prosa es escueta y el interés es guiado por el autor hacia la relación entre erotismo, naturaleza y poesía, en una leve introducción inicial: "Tal vez el amor y la naturaleza fueron desde muy temprano los yacimientos de mi poesía" (Confieso 22). No podemos decir que captamos intuitivamente aquello en el texto del poema, pues es demasiado explícito. Tampoco vale aquí decir que la poesía omite, insinúa; mientras la prosa lo dice todo. Aquí la prosa es la que insinúa, la que calla y sin embargo nos da la clave del despertar erótico del niño.

Confieso que he vivido prueba lo que la crítica (Loyola 1964; Aguirre 1973) y el mismo Neruda sostuvieron toda la vida: el contenido biográfico de su poesía. Pero ¿qué es lo que lleva a un escritor a expresar una misma experiencia en varias formas literarias, revelando una constante inconformidad con el producto que la obra revela? Neruda vuelve una y otra vez sobre sus pasos, creando un flujo incesante de escritura, como si ésta fuera siempre insuficiente para captar en plenitud la experiencia. Así sucede con el tema del padre. El primer adjetivo que Neruda otorga al padre en el Memorial es el de "brusco" (I: 25). Versos como "la puerta temblaba / ... las puertas asustadas / disparo de pistolas / y una voz alta / recriminaba hostil", definen una relación patriarcal, de timidez y dominio sobre el poeta niño: "Mi pobre padre duro", dirá en otra parte del Memorial (27). La madre y la mamadre, en cambio, son presencias relacionadas siempre con cualidades de ternura, con objetos cotidianos como el pan, la luz y la poesía: A la mamadre, "nunca pude decir madrastra" (I: 19), la define en términos de comida: La vida te hizo pan / y allí te consumimos" (I: 20$)$.

En el mundo infantil de Neruda, la relación poesía-naturaleza está también asociada a la figura de estas mujeres tutelares más que a la figura masculina. Pero el poder de transformación de la naturaleza mediante el uso de la fuerza y de la energía, la capacidad de la lucha contra la adversidad del entorno hostil del sur, está vista como una virtud del padre y se alude a ella con orgullo en abundantes pasajes de las Memorias: el padre es el nuevo conquistador de la zona aislada de la Araucanía, su pitazo de tren se abre a la luz de la modernidad, es anuncio de una era nueva simbolizada en la vocación de servicio público del oficio de ferroviario, uniendo los pueblos al comercio y a las comunicaciones. Orgullo de clase proletaria, visible en párrafos como:

Era conductor de un tren lastrero ... Se había acostumbrado a mandar y a obedecer. A veces me llevaba con él. Picábamos piedra en Boroa, corazón silvestre de la frontera, escenario de los terribles combates entre españoles y araucanos. (17)

Aunque todo ello se encuentre difuminado en los recuerdos, la dura realidad de la lucha por la vida ha ocupado un lugar preponderante en la conciencia del niño. En el mundo poético de estas memorias, Neruda integra sin conflictos las experiencias iniciales y fundamentales al manantial inagotable de su poesía: por un lado el mundo familiar como el todo que rodea la casa, el patio, el lugar donde escribe "en el segundo piso", y por otro lado el mundo exterior, natural e histórico, expresado en la lluvia como "el primer personaje importante", la naturaleza del sur, el bosque de música de aves y de silencio, poblado de animales, objetos y vida secreta: los incendios, la destrucción de la madera y su reflorecimiento. 
Todo tiempo pasado es eternamente presente, sostiene Eliot en Four Quartets. ${ }^{6}$ La intermitencia a que Neruda se refiere en su introducción, es la posibilidad de ver el pasado como presente, es decir anulándolo. Neruda no siente la necesidad de redimir el pasado para cuestionarlo, repensarlo o revivirlo. Lo hecho y lo vivido bien hecho y vivido está. La conciencia poética del enunciante que dice que está habitado por el bosque y la lluvia, es la misma conciencia que busca sus raíces perdidas y las encuentra en la manos de su mujer o en los cántaros de greda de Quinchamalí, cuando ya es viejo. No ocurre lo mismo en The Words de Sartre ni en Coto vedado de Goytisolo (1988), en cuyas memorias el pasado es siempre reinterpretado y repensado a la luz de la evolución posterior o de la postura vital e ideológica del memorialista. La construcción biográfica de Neruda es metafórica y como tal no se detiene en las transiciones de la experiencia sino en su simultaneidad. Sus zonas de concomitancia son sutiles y permiten el trasvasijamiento desde el verso a la prosa, sin ruptura ni sobresalto. Para construir y crear la imagen de sí mismo, Neruda recurre a "los otros" y despliega esa galería enorme de escritores, artistas y políticos, que al igual que en La arboleda perdida (1989) de Rafael Alberti, ponen el marco adecuado a una vida notable, o al menos significativa. Esta imagen de sí mismo la construye Neruda recurriendo a veces al humor (García Lorca), al ridículo (Vicente Huidobro) o a la violencia del ataque verbal y los juegos de palabras (Pablo de Rokha). Para cualquier lector culto, estos recortes caricaturescos no pueden ser tomados como retratos totales y verdaderos. El mismo Neruda los retoca a cada momento, con mayor o menor objetividad. ${ }^{7}$ Procede como una Ariadne a la inversa. En su recorrido ha perdido el pasado y quiere unificarlo. El hilo de la memoria es el presente y la meta es teleológica, hacia la profundidad y la comprensión del camino ya recorrido y conocido. Todo se hace presente en la metáfora. La única mujer que existe es la de ahora y aquí: Matilde. Ella contiene en su bondad y en su belleza todas las otras mujeres que algunos críticos reclaman como ausentes (Shopf 206). Ellas están, sin embargo, en la gran metáfora que es Matilde, pues tampoco ella es la totalidad.

Tres episodios del primer capítulo de las memorias muestran una interesante relación de correspondencia con la poesía. Ellos son el episodio del cisne y el del descubrimiento de la poesía, incluidos en el excurso "Mi primer poema" (Confieso 30). El tercero se titula "La timidez", igual que el poema del Memorial de Isla Negra (I: 55). Mirada desde estas dos perspectivas, el relato del encuentro con la poesía se relaciona con lo misterioso y lo desconocido: lo inexplicable. El poema "La poesía", se inicia como un titubeo entrecortado por los puntos suspensivos y las elisiones: "Y fue a esa edad /.../ llegó la poesía / a buscarme. No sé, no sé de dónde / salió, de invierno o río. / No sé cómo ni cuándo" (I: 51). Poesía que no era "palabras ni silencio," sino "quemadura" que es necesario descifrar en el proceso de la escritura o de la experiencia creadora. En la descripción en prosa

\footnotetext{
${ }^{6}$ Olney $(1980,240)$ analiza en profundidad la presencia autobiográfica en la poesía de Valéry, Wright y Eliot.

${ }^{7}$ De Huidobro dirá: "Hay una lucha entre el juego y el fuego, entre la evasión y la inmolación" (394). De García Lorca: "Ingenuo y comediante, cósmico y provinciano, músico singular, mimo espantadizo y superticioso, radiante y gentil, era una especie de resumen de las edades de España, del florecimiento popular" (170).
} 
titulada "Mi primer poema" se unen la fábula, el mito y la poesía. Más creíble en términos de la biografía, que la anécdota del padre que responde “¿De dónde lo copiaste?” ante el primer poema mostrado por el hijo, es la descripción del verano abrasador de Temuco, el encuentro fascinante con la naturaleza, con los insectos y con el canto de los pájaros que emergen del follaje selvático. El lector entiende muy bien lo que Neruda quiere decir: allí, y no en la anécdota, nace su poesía. Pues con seguridad el poema mostrado al padre no es otro que el rescatado por Margarita Aguirre $(1973,56)$, como dedicatoria a su mamadre, escrito en una tarjeta en mayo de 1915: "De un paisaje de áureas regiones, yo escogí para darle, querida mamá, esta humilde postal. Neftalí”. En este preciso lugar las memorias conectan con el episodio del cisne. En el Memorial el poema titulado "Los cisnes del Lago Budy", parodia el tema y el título de uno de los más conocidos poemas de los escolares chilenos de este siglo: "La fuga de los cisnes", de Augusto Winter (1868-1952), empleado en la Biblioteca Municipal de Puerto Saavedra, cerca de Temuco, y encargado de proveer los libros que Neruda traga como una avestruz, "sin digerir" (33). Una vez más Neruda vuelve a la fábula, reviviendo y recreando el viejo símbolo modernista, hecho ahora realidad bajo su experiencia sureña privilegiada: los cisnes son aquí y en su poesía, tan reales como los patos o las gallinas y además "no cantan cuando mueren" (Confieso 31). Parecido afán de mitificar y metaforizar un pasado edénico tiene el episodio "La casa de las tres viudas"(34) y "El amor junto al trigo"(40). Son ellas ceremonias iniciáticas y están escritas con maestría de gran prosista y narrador. El niño perdido en los caminos indescifrables de la cordillera, el encuentro con la mansión acogedora donde se lee Fleurs du mal en francés y se sirve en vajilla de plata guisos nunca repetidos, regados por rancios vinos franceses en cristales iluminados por candelabros. He aquí la iniciación social y sexual. El término del viaje, corresponde a la escena de amor bajo la parva de trigo con una mujer sin rostro y sin nombre. Sospecha que pudo haber sido una de las dueñas de casa, pues al momento del desayuno, "su sonrisa se hacía más grande y más profunda, se abría dentro de mi cuerpo" (Confieso 43).

Se nos hace difícil pensar ahora en el rasgo de la timidez que Neruda describe constantemente. No calza ni con el político ni con el perseguido, ni menos con el irreverente poeta que rompe y destruye formas y cánones poéticos consagrados, con el fuego violento de su poesía y de su palabra-dardo. En el poema del Memorial timidez significa soledad: "quise que no me vieran / que no se conociera mi existencia". Y la lucha por mantener incólume el mundo original, el oscuro rincón de la poesía: "para seguir allí, pero invisible / estar presente en todo pero lejos / guardar mi propia identidad oscura / atada al ritmo de la primavera" (I: 55).

Las memorias se refieren al extraño e intrincado proceso de convivencia de estas fuerzas opuestas: timidez y orgullo, soledad e instinto gregario. Estas contradicciones pueden observarse en la prosa y la poesía. En el poema dice: "ansioso de la vida y temeroso, / cerca del agua sin beber el frío, / cerca del fuego sin beber la llama” (I: 56). En la prosa:

Yo hubiera querido morir abrasado en esa hoguera secreta, ahogarme en el pozo de enigmática profundidad, pero no me atrevía a tirarme al fuego o al agua. Y como no encontraba a nadie que me diera un empujón, pasaba por las orillas de la fascinación, sin mirar siquiera, y mucho menos sonreír. (Confieso 53) 
La capacidad de escrutar los insondables melindres de la conciencia es siempre implacable en estas Memorias: "La timidez es una condición extraña del alma, una categoría, una dimensión que se abre a la soledad" (53). Su prosa nos permite acceder a un Neruda vigilante y atento a los procesos de la subjetividad y de su propio mundo sicológico. Anota y clasifica los sentimientos contradictorios y oscuros que salen luego en su poesía, a dentelladas de imágenes: "como la voz de un perro herido / desde el fondo de un pozo": "La timidez" (I: 56).

El primer libro del Memorial de Isla Negra abarca desde 1904 hasta 1921, fecha en que el poeta se traslada a Santiago. Ocupa, por lo tanto los dos primeros capítulos de las memorias. Incluye la descripción del ambiente bohemio del Santiago de la década del veinte, "La casa de pensión" (47), es decir los crepúsculos de Maruri, "La Federación de Estudiantes" (56), el homenaje a sus amigos muertos (Romeo Murga, Rojas Giménez), las extravagancias de otros, hasta el regocijo del primer libro publicado: Crepusculario (1923). Al segundo capítulo de Confieso corresponde la visión del poema "El niño perdido", que describe la evolución del niño al hombre, el paso de una máscara (persona) a la otra: "La máscara del niño fue cambiando" (I: 70). Y la misma idea de pérdida, de vivir a la intemperie, que es el tema de "El tren nocturno" (I: 95), está desarrollada en la prosa de las memorias: el cambio de la madera al adobe o barro en las construcciones de las casas, el paisaje de robles y araucarias que cede el paso a los álamos tristes y desolados de la zona central: "Hasta ahora, sigo siendo un poeta de la intemperie, de la selva fría que perdí desde entonces" (Confieso 48). La imagen del poema es elocuente: "supe, porque sangraba,/ que me habían cortado las raíces" (I: 99). La culminación del segundo capítulo de Confieso, se relaciona con la fruición sensual del primer libro impreso y de la devoción por el lenguaje como objeto lúdico, de placer y conocimiento. Y el despertar de la conciencia política en la vida social y estudiantil de la época: la revista Claridad, los movimientos de emancipación estudiantil y popular:

Los estudiantes apoyábamos las reivindicaciones populares y éramos apaleados por la policía en las calles de Santiago. A la capital llegaban miles de obreros cesantes del salitre y del cobre. Las manifestaciones y la represión consiguientes tefían trágicamente la vida nacional. (Confieso 76)

Neruda culmina esta sección con un texto de gran belleza lírica: "La palabra". Bastaría que el poeta hubiese colocado este texto en unidades independientes para convertirlo en oda o en otro de sus mejores poemas en verso. El resultado sería el siguiente:

Brillan como piedras de colores

saltan como peces platinados, son espuma, hilo, metal, rocío ...

Persigo algunas palabras. Son tan hermosas

que las quiero poner todas en mi poema ...

las agarro al vuelo cuando van zumbando

Y las atrapo, las limpio, las pelo

me preparo frente al plato,

las siento cristalinas

vibrantes, ebúrneas, vegetales ... etc. 
Fiesta de sonido y del sentido. El paralelismo métrico y acentual de los dísticos iniciales, las enumeraciones que le siguen, las vocales brillantes en contraste con las sombrías en una orquestación fascinante: "hilo, metal rocío" vs. "vibrantes, ebúrneas, vegetales" conforman una totalidad difícil de desentrañar, propias de su mejor poesía. Neruda mezcla en su autobiografia la historia personal y epocal con la creación literaria, la poesía y la ficción pura. Su procedimiento es el de captar lo significativo en un detalle o momento crucial de una escena. Con ello ofrece la visión panorámica no sólo de la vida del autor, sino la de su circunstancia histórica y la de su entorno y visión particular del mundo. ${ }^{8}$ Es la propia memoria, a través del texto, la que establece un diálogo con la historia, con las circunstancias concretas de un tiempo y con el lector que es juez, testigo interesado y tribunal inquisidor. Más aun en el caso de Neruda cuya figura como escritor y como político es tan relevante como para despertar interés en ámbitos más extensos que los exclusivamente literarios. Es verdad que hay grandes omisiones en el devenir de estas memorias, especialmente para aquellos contemporáneos que buscan una referencia más detallada de dos de sus grandes fuentes literarias: el compromiso político y el amor. Son muchos los decepcionados y los que, por ese camino, pueden descubrir grandes contradicciones y deconstrucciones (Labanyi 1990; Shopf 1991). El postulado de una "vida hecha de todas las vidas" no pasa de ser una buena intención puesto que la primera persona, el yo, es la que ocupa todos los espacios, a pesar de la galería de toda clase de personajes que el libro incluye en sus partes finales: Castro, Codovila, Stalin, Frei, como muestras de intransigencia y dogmatismo. Allende, Prestes y una gran cantidad de escritores notables, completan la galería de las virtudes. Con todos ellos y especialmente con los equivocados, Neruda comparte "esa responsabilidad que nos alcanza a todos", especialmente frente a los errores. La autocrítica y el análisis "-_elementos esenciales de nuestra doctrinanos daba las armas para impedir que cosas tan horribles pudieran repetirse" (Confieso 434). Neruda no sigue ningún gran modelo en esta re-construcción vital, sino el de su propia concepción poética, de la que aquí no se aparta. Las mujeres continúan sin rostro y sin voz, como en aquella primera experiencia bajo la parva de trigo. ${ }^{9}$ ¿Y qué importa todo esto, a no ser la mera satisfacción de nuestra curiosidad morbosa para indagar más allá de lo que nos entrega la literatura? No todo es explícito en una autobiografía, que "es un brazo quebrado de la historia" (Gass 1993). El que desee descubrir las claves de la conversión marxista de Neruda puede encontrarlas a partir de sus más tempranas experiencias: el oficio proletario del padre, el abusivo e injusto colonialismo inglés y las divisiones de clases en su experiencia en India (123) y, sobre todo, la experiencia de la guerra civil española que lo obliga a tomar una decisión entre el anarquismo, el fascismo y la muerte por un lado y las necesidades de los exiliados en París, la odisea del Winnipeg, el Frente Popular de Chile de 1938 y la concepción de una poesía "como el pan", blanca y

\footnotetext{
${ }^{8}$ Puesto que "There are no rules or formal requirements binding the perspective autobiographer no restraints, no necessary models" (Fernández 9)

${ }^{9}$ Albertina Azócar, a quien Neruda enviara más de cien cartas de amor, ni siquiera se nombra en el libro. Delia del Carril, "mi mujer de entonces" (180), es apenas "pasajera suavísima", a pesar de haber sido su compañera por casi veinte años. María A. Agenaar (152), con la que tuvo una hija, es una sombra invisible. De Jossie Blis ni siquiera sabemos el nombre original javanés.
} 
universal, solidaria y humana: "Creo haberme definido ante mí mismo como un comunista durante la guerra de España" (191). ${ }^{10}$ A pesar de su admiración por la Unión Soviética y por sus poetas y artistas, Neruda se anticipa a señalar que "la existencia de un dogmatismo soviético en las artes durante largos períodos no puede ser negada" (Confieso 273). Esta autocrítica, que forma parte también del último libro del Memorial de Isla Negra ("Sonata Crítica"), otorga a Neruda una dimensión notable que la crítica ha sido reacia en señalar. Con igual valentía y dignidad no tenía por qué callar frente a los errores del dogmatismo revolucionario de algunos escritores cubanos y enterrar de una sola plumada "a los arribistas políticos y literarios de nuestra época" (445) que pretendían dirigir y enmarcar su conducta vital.

Resulta dramática la relectura de las páginas finales de Confieso que he vivido para los que tuvimos que leer un libro despedazado, forrado en páginas de diario para ocultarlo de quienes lo tenían prohibido en Chile, esgrimiendo que Neruda no había escrito esas páginas. Buena excusa para ocultar el miedo. El triunfo de la Unidad Popular y el ascenso de la clase proletaria y media chilena al poder debía mucho a la actividad constante de Pablo Neruda recorriendo "prácticamente todos los rincones de Chile, desparramando mi poesía entre la gente de mi pueblo" (351). Ese mismo pueblo lo hizo Senador, candidato a la Presidencia de la República, Embajador en Francia, pero por sobre todo, lo proclamó su poeta: "Es memorable y desgarrador para el poeta haber encarnado para muchos hombres durante un minuto, la esperanza" (458). Pero es el mismo que ya había escrito un libro con señales de pesimismo apocalíptico en el que alude profética y poéticamente a ese espacio de tinieblas en que murió:

Piedad para estos siglos y sus sobrevivientes alegres o maltrechos, lo que no hicimos fue por culpa de nadie, faltó acero.

El acero que faltó lo pusieron "nuestros heroicos aviadores" (474) que bombardearon a Chile en septiembre de 1973, apoyados por las fuerzas políticas con las que Neruda nunca tranzó y con los representantes que reciben aquí su epitafio de muerte ${ }^{11}$ y que lo lleva a evocar "la Blitz Krieg de la aviación nazi contra indefensas ciudades extranjeras" (475).

Neruda escribe el final de estas Memorias, "sólo a tres días de los hechos incalificables que llevaron a la muerte a mi gran compañero, el presidente Allende" (475). Es decir a una semana antes de su muerte que pone el verdadero punto final a sus recuerdos con la primera manifestación de protesta en el cementerio, el día de su entierro: su poesía no había cantado en vano. Más que una revelación autobiográfica, estas Memorias quieren ratificar la constante relación entre vida e ideología, conducta y poesía, en la estética y la ética de su

\footnotetext{
${ }^{10}$ Los interesados en detalles biográficos puden recurrir al excelente libro de memorias de Jorge Edwards Adios, poeta ... (1990) para la revisión de la crísis política del mundo socialista "iniciada en 1956 por la denuncia de los crímenes de Stalin en el XX Congreso del PC de la Unión Soviética, y cuya repercusión en la poesía nerudiana es evidente" (135). Para su vida amorosa, el libro Mi vida junto a Pablo Neruda (Urrutia, 1985).

"Frei y Zaldívar (468) y Radomiro Tomic (469).
} 
autor. La supremacía de los valores en los que creía y defendió constantemente: la solidaridad con los pobres y los que nada tienen, la posibilidad de una sociedad más justa, más humana y más culta en la faz de la tierra. Éste es el programa de su poesía y estas Memorias no hacen más que confirmarlo.

\section{Obras cITADAs}

Aguirre, Margarita. Las vidas de Pablo Neruda. Buenos Aires: Grijalbo, 1973.

Alberti, Rafael. La arboleda perdida. Barcelona: Seix Barral, 1989.

Alone (Hernán Diaz Arrieta). Memorialistas chilenos. Santiago de Chile: Zig-Zag, 1960. Edwards, Jorge. Adios, poeta ... Barcelona: Tusquet, 1990.

Fernández, D. James. Apology to Apostrophe: Autobiography and the Rhetoric of Self Representation in Spain. Durham: Duke University Press, 1992.

Gass, H. William. "Autobiography: essay as nomenclature". Unpublished reading. Washington University. Saint Louis MO, 1993.

Goytisolo, Juan. Coto vedado. Barcelona: Seix Barral, 1988

Obra inglesa de José M. Blanco White. Barcelona: Seix Barral, 1972.

González-Cruz, Luis F. Pablo Neruda y el Memorial de Isla Negra. Miami: Universal, 1972.

Gusdorf Georges. "Conditions and Limits of Autobiography". Ed. James Olney. Autobiography: Essay Theoretical and Critical. Princeton: Princeton University Press, 1980, 28-48.

Labanyi, Jo. "The construction/deconstruction of the self in the autobiographies of Pablo Neruda and Juan Goytisolo". Forum for Modern Language Studies 3/26 (1990), 212-221.

Loyola, Hernán. Los modos de autorreferencia en la obra de Pablo Neruda. Santiago de Chile: Aurora, 1964.

Neruda, Pablo. Confieso que he vivido. Memorias. Barcelona: Seix Barral, 1974. Obras completas. Buenos Aires: Losada, 1956.

Para nacer he nacido. Barcelona: Seix Barral, 1977.

Olney, James. Ed., Autobiography: Essay Theoretical and Critical. Princeton: Princeton University Press, 1980.

Metaphors of Self: The Meaning of Autobiography. Princeton: Princeton University Press, 1972.

Ortega y Gasset, José. “Sobre unas memorias”. Obras Completas III. Madrid: Revista de Occidente, 1947.

Pérez Rosales, Vicente. Recuerdos del pasado. Santiago de Chile: Biblioteca de Escritores Chilenos, 1910.

Pope, Randolph D. La autobiografia española hasta Torres Villarroel. Frankfurt: Bern Lang, 1974.

Prats González, Carlos. Memorias. Testimonio de un soldado. Santiago de Chile: Pehuén, 1985.

Shopf, Federico. "Confieso que he vivido de Neruda: identidad y máscaras". Jorge Narváez Ed. La invención de la memoria. Santiago de Chile: Pehuén, 1988, 201-225. 
Sicard, Alain. El pensamiento poético de Pablo Neruda. Madrid: Gredos, 1981. Urrutia, Matilde. Mi vida junto a Pablo Neruda. Madrid: Seix Barral, 1985.

Zambrano, María. La confesión: método y género literario. México: Luminar, 1989. 